\title{
Thermodynamic Stability of Myoglobin-Poly(Ethylene Glycol) Bioconjugates: a Calorimetric Study
}

\author{
Chiara Pelosi a, b, *, Francesca Saitta c, *, Frederik R. Wurm ${ }^{\text {b, Dimitrios Fessas }}{ }^{\text {c, Maria }}$ \\ Rosaria Tinè ${ }^{a}$ and Celia Duce ${ }^{a}$. \\ a: Dipartimento di Chimica e Chimica Industriale, Università di Pisa, Via Moruzzi, 56124, Pisa, \\ Italy. \\ b: Max-Planck-Institut für Polymerforschung, Ackermannweg 10, 55128 Mainz, Germany. \\ c: Dipartimento di Scienze per gli Alimenti, la Nutrizione e l'Ambiente, DeFENS, Università degli \\ Studi di Milano, Via Celoria 2, 20133, Milano, Italy \\ * These authors contributed equally to the work.
}

Corresponding authors: Maria Rosaria Tinè, mariarosaria.tine@unipi.it, +39 0502219268; Dimitrios Fessas, dimitrios.fessas@unimi.it, +390250319219.

\begin{abstract}
PEGylated proteins are widely used for therapeutic applications, therefore a fundamental understanding of the conjugates' structure and their behaviour in solution is essential to promote new developments in this field. In the present work, myoglobin-poly(ethylene glycol) conjugates were synthesized and studied by using differential scanning calorimetry and UV-visible spectroscopy to obtain information on the bioconjugates' thermodynamic stability, also focusing on the PEG's role on the solvent-protein surface interaction. The overall results of this study indicated a thermal destabilization of the proteins that follows the extent of the bioconjugation without, however, compromising the native structure which remains functional. Moreover, the myoglobin PEGylation prevented the post-denaturation aggregation phenomena and enhanced the protein thermal reversibility. The thermodynamic interpretation of the data indicated that the bioconjugation influences the solvent-exposed protein surface difference between native and denatured state, contributing to the interpretation of the overall protein modification and functionality.
\end{abstract}

Keywords: PEGylation, calorimetry, protein unfolding, unfolding reversibility, proteinpolymer conjugation. 


\section{Introduction}

The biotechnology evolution of the last century has underlined the great potentialities of protein and peptides as therapeutic agents. Nowadays more than 90 protein based compound are industrially produced and used as potent drugs for the treatment of severe diseases [1,2]. Despite their usefulness, they often exhibit several drawbacks, among which there are short shelf-life, low solubility in water and short life time inside the body [3]. Several strategies have been developed to avoid or decrease these limits, reducing the production costs of the drugs and their dosing frequency for patients [4]. One of the most promising strategies is bioconjugation, that consists in the covalent attachment of synthetic polymers to the proteins in order to form protein-polymer conjugates [5]. Poly(ethylene glycol) (PEG) is the most common polymer in bioconjugation [6]. Today there are 13 PEG-protein conjugates approved from U.S. Food and Drug Administration and used for therapeutic purposes, while many others are currently under clinical trials [7-10]. The conjugates can perform several functions: replacement therapies for native enzyme deficiencies (Adagen ${ }^{\circledR}$, Oncaspar ${ }^{\circledR}$, Krystexxa ${ }^{\circledR}$ ), stimulation of immune responses (PEG-Intron ${ }^{\circledR}$, PEGASYS ${ }^{\circledR}$, Plegridy ${ }^{\circledR}$ ), regulation of blood cells production (Mircera $\AA$, Omontys ${ }^{\circledR}$, Adinovate ${ }^{\circledR}$ ), stimulation

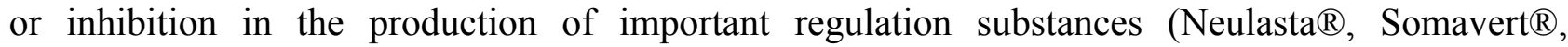
Macugen $(\mathbb{R})$ and can be used against several diseases. The covalent bond of the polymer induces the formation of a protective shield around the protein-based drug, resulting often in an improvement of some properties, as major drug solubility, less in vivo and in vitro aggregation, less immunogenicity and allergenicity, minor degradation and opsonisation and minor kidney clearance [11-14]. The overall effect is an improvement in the drug pharmacokinetics, with an increasing of its life time and a reduction of the necessary dosage frequency for patients. Moreover the PEGylation of surfaces reduces the adsorption of other proteins that occurs in a physiological media, thanks to the high hydration of the hydrophilic polyether backbone and to an increased steric repulsion on the surface [15]. These shielding features are indicated as stealth effect of PEG.

Beyond the pharmacologic evaluation, the thermodynamic and structural protein stability and its residual activity after the bioconjugation process [16-19] are fundamental issues that have to be explored in the development of any new pharmaceutical protein, in order to understand its potentialities.

However, in our knowledge, just few studies regarding the thermodynamic stability of proteinpolymer conjugates appear in the literature [20-23] and despite some hypothesis have been advanced [23,24], the molecular mechanism by which PEGylation changes the protein thermodynamic stability and its behaviour in solution remains uncertain and the effects have to be evaluated case by case.

In the present work, myoglobin of equine skeletal muscle, a single chain protein containing 153 amino acid residues, was selected for the synthesis of myoglobin-poly(ethylene glycol) conjugates. Such systems were studied by using differential scanning calorimetry and UV-visible spectroscopy in order to discriminate the thermodynamic contributions due to PEGylation on the overall protein stability, also focusing on the PEG's role on the solvent-protein surface interaction that dictate denaturation reversibility and/or aggregation phenomena. Despite the simple primary and tertiary structure (with 19 lysinic residues available for bioconjugation), this protein shows low thermal reversibility [25] and high tendency to aggregate after the thermal denaturation and represents a sensitive model with respect to the properties that we propose to investigate. 


\section{Experimental section}

\subsection{Materials}

Myoglobin of equine skeletal muscle was purchased from Sigma Aldrich, whereas Dulbecco's phosphate buffered saline without calcium and magnesium (DPBS) was purchased from Gibco/Life Technologies (Germany) and used as received. Borate buffer $50 \mathrm{mM}$ was prepared making a solution of sodium tetraborate $50 \mathrm{mM}$ (distilled water and $\mathrm{Na}_{2} \mathrm{~B}_{4} \mathrm{O}_{7} \cdot 10 \mathrm{H}_{2} \mathrm{O}$, Sigma Aldrich Germany); the $\mathrm{pH}$ was adjusted with $\mathrm{HCl} 0.1 \mathrm{M}$ until to be $\mathrm{pH}=8.8$. Poly(ethylene glycol) monomethyl ether (PEG) $\left(\mathrm{M}_{\mathrm{n}}=5 \mathrm{kDa}\right)$ was purchased from Fluka and post-modified following the procedure reported by Zalipski [26], obtaining N-hydroxysuccinimide-poly(ethylene glycol) (PEGNHS). Sephadex G-50 medium (Sigma Aldrich) was allowed to swallow in water overnight before use, following the proportion Sephadex/water $=10 \mathrm{~mL} / 50 \mathrm{~mL}$; when the column was not in use, it was stored in a solution of $5 \% \mathrm{EtOH}$ at $4^{\circ} \mathrm{C}$.

The synthesis and characterization of the PEGylated samples My-PEG (1) and My-PEG (2) was performed following a procedure reported in detail in the literature for analogue conjugates [27]. Suffice here to say that for the two bioconjugates we obtained purity $=99 \%$, dispersity $Đ=1.051$, number-average molar mass $\mathrm{M}_{\mathrm{n}}=47.490$ and average number of attached chains $=3.3$ for $M y-P E G$ (1), and purity $=97.5 \%$, dispersity $\mathrm{D}=1.008$, number-average molar mass $\mathrm{M}_{\mathrm{n}}=63.970$ and average number of attached chains $=5.2$ for $M y-P E G$ (2).

\subsection{Differential Scanning Calorimetry (DSC)}

Calorimetric measurements were carried out in solution with a protein concentration of about $1.5 \cdot 10^{-4} \mathrm{M}$ in DPBS at $\mathrm{pH} 7.0$ with a Setaram Micro-DSCIII apparatus, equipped with $1 \mathrm{~mL}$ hermetically closed cylindrical pans, at $0.5^{\circ} \mathrm{C} \cdot \mathrm{min}^{-1} \mathrm{scan}$ rate in the temperature range from $20^{\circ} \mathrm{C}$ to $95^{\circ} \mathrm{C}$. Some measurements were also performed by using the TA Instruments Nano-DSC (6300) equipped with capillary cells at the same scan rate. For all the experiments, a heating-cooling cycle was scheduled followed by a second heating scan. Data were analyzed by means of the software THESEUS [28] following procedures reported in previous studies [29]. Here it is sufficient to say that the excess molar heat capacity $C_{P} \operatorname{exc}(T)$, i.e. the difference between the apparent molar heat capacity $C_{P}(T)$ of the sample and the molar heat capacity of the "native state", $C_{P, N}(T)$, was recorded across the scanned temperature range. The heat capacity drop, $\Delta_{d} C_{P}$, across the signal was affected by a rather large error and was therefore not taken into account in the present work. The area underlying the recorded peaks, so treated, directly corresponds to the relevant denaturation enthalpy, $\Delta_{d} H^{\circ}$, in $\mathrm{kJ} \cdot \mathrm{mol}^{-1}$ units. Errors were evaluated on the basis of at least three replicas. The fit attempts based on the denaturation thermodynamic models were accomplished using the nonlinear Levenberg-Marquardt method [30]. The errors of each fitting parameter were calculated with a $95.4 \%$ confidence limit by the Monte Carlo simulation method.

\subsection{UV-Vis measurements}

The UV-Vis absorbance spectra of the samples' solutions in DPBS were registered with a Jasco V-550 UV/VIS spectrometer in the range $200-600 \mathrm{~nm}$. The initial protein concentration in the samples was between 1 and $1.5 \mathrm{mg} / \mathrm{ml}$. The spectra were therefore normalized to the same protein concentration $(1 \mathrm{mg} / \mathrm{mL})$, using the intensity value recorded at $280 \mathrm{~nm}$. 


\section{Results and discussion}

\subsection{Influence of bioconjugation on the reversibility of the protein thermal denaturation}

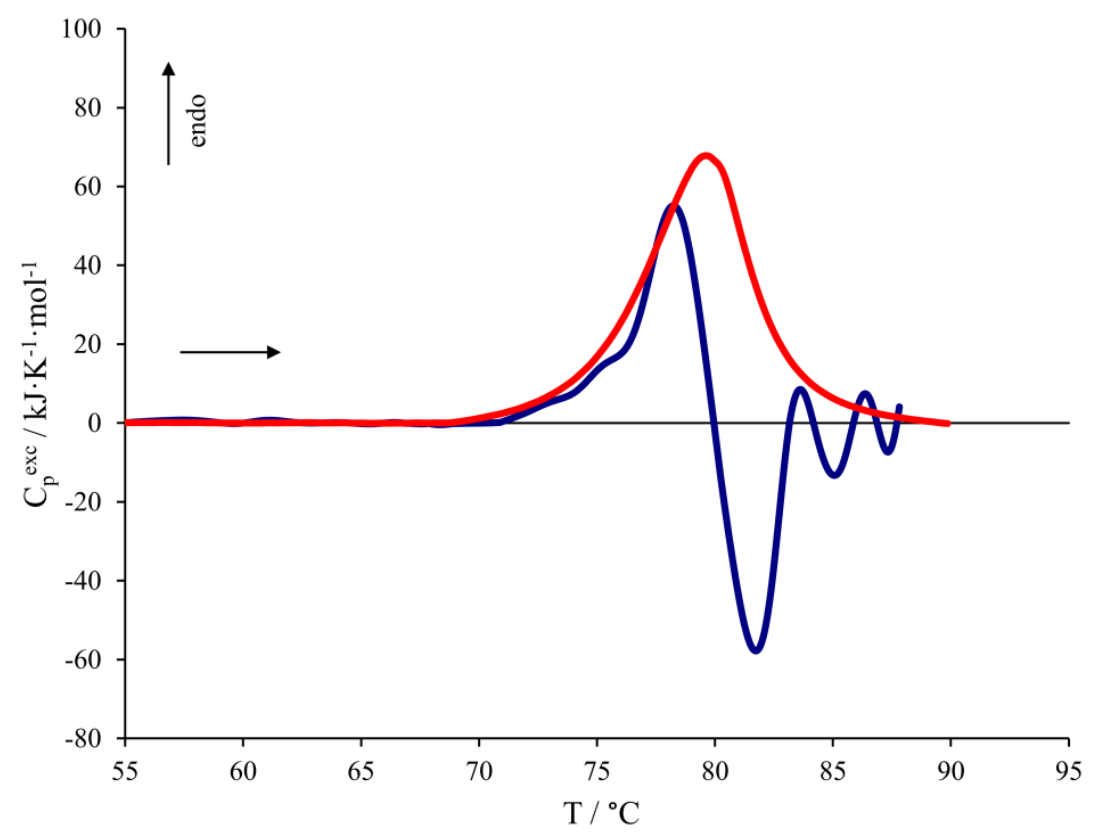

Fig. 1: Myoglobin thermal denaturation.

Thermograms for unmodified myoglobin $\left(1.5 \cdot 10^{-4} \mathrm{M}\right.$ in DPBS, $\mathrm{pH} 7.0,0.5^{\circ} \mathrm{C} \cdot \mathrm{min}^{-1}$ scan rate) obtained by using both a micro-DSC with cylindrical cell (blue curve) and a nano-DSC with capillary cells (red curve).

The blue curve was smoothed in order to reduce the noise due to aggregation effects.

The blue curve in Fig. 1 reports the micro-DSC thermogram (with cylindrical cells) of the unmodified myoglobin. We observed a complex signal, namely an endothermic peak followed by a strong exothermic contribute ending with a noisy trace. This is a typical picture of overlapping processes, i.e. thermal denaturation of the protein with concomitant aggregation effect as expected for the myoglobin at this $\mathrm{pH}$ in line with the literature [31].

For sake of clarity and in an attempt to obtain information of the thermal stability of the protein in these conditions, despite the aggregation phenomena we also used a capillary cell DSC calorimeter and the resulting trace is reported in the same figure (red curve) showing a single endothermic peak. Indeed, the use of capillary cells seemed to mitigate the aggregation and/or precipitation phenomena. However, in both cases, the denaturation process resulted irreversible as revealed by the second heating scan (flat traces not reported).

These results were in agreement with the information obtained by the spectroscopic analysis (UV absorbance, $280 \mathrm{~nm}$; extinction coefficient: $1.66 \mathrm{mg} \cdot \mathrm{cm}^{-1}$, [32]). Indeed, the occurrence of a thermal-induced aggregation of myoglobin was confirmed by the determination of the protein concentration in solution before and after the thermal scan, which showed a consistent decrease in protein concentration after the calorimetric run (reduction of $45 \%$ ) besides the formation of a visible red precipitate. 

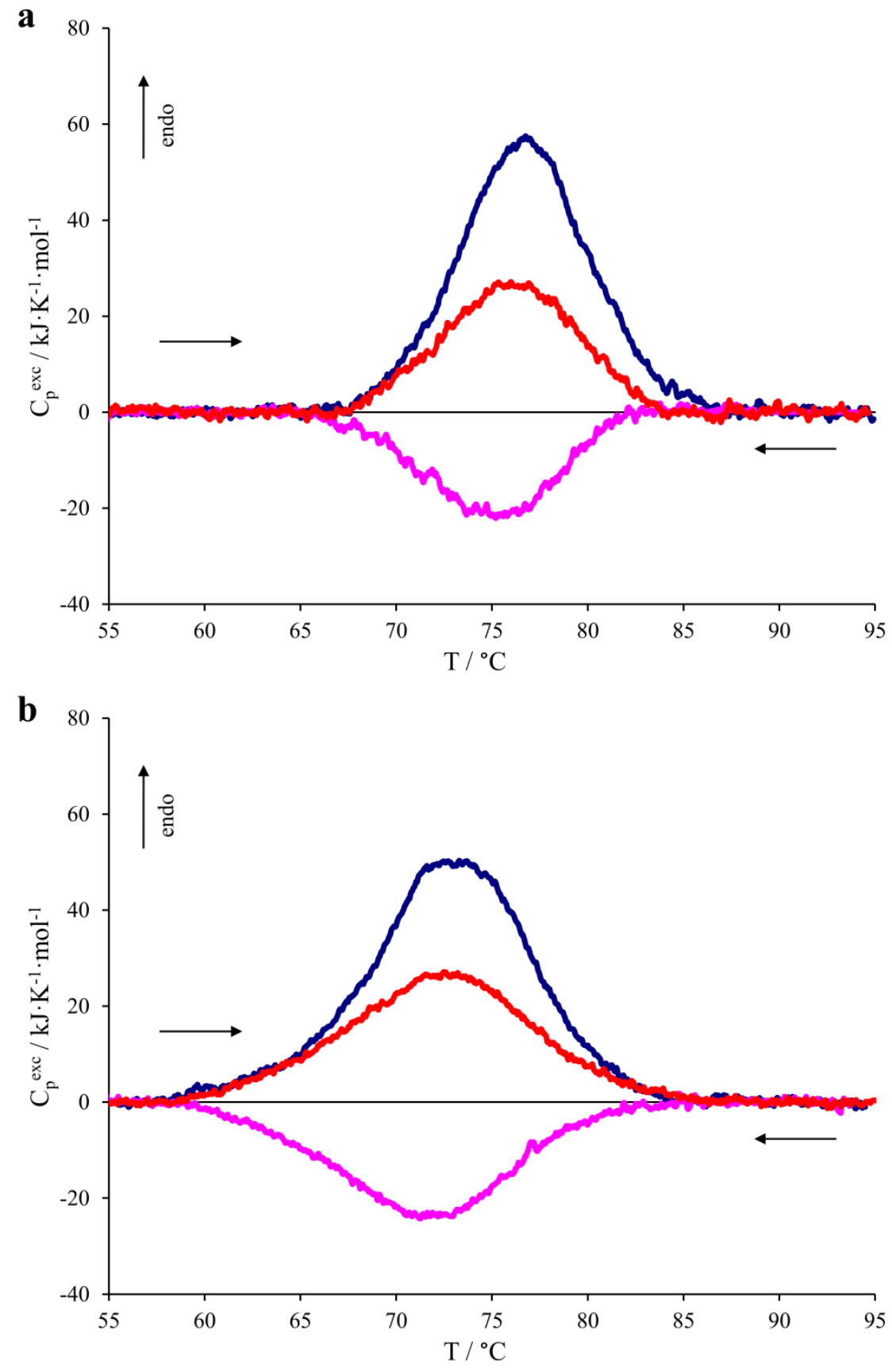

Fig. 2: PEGylation effect on the bioconjugates thermal stability.

Micro-DSC thermograms for My-PEG (1) and My-PEG (2) solutions $\left(1.5 \cdot 10^{-4} \mathrm{M}\right.$ in DPBS, pH 7.0, $0.5^{\circ} \mathrm{C} \cdot \mathrm{min}^{-1}$ scan rate) in panel $a$ and $\mathrm{b}$, respectively. First heating scans from 20 to $95^{\circ} \mathrm{C}$ (blue curves); cooling scans from 95 to $20^{\circ} \mathrm{C}$ (purple curves); second heating scans from 20 to $95^{\circ} \mathrm{C}$ (red curves).

Fig. 2 reports the micro-DSC traces obtained through a heating/cooling cycle followed by a second heating scan for the My-PEG (1) and My-PEG (2) proteins (panel $a$ and $b$, respectively). In both cases we observed a single endothermic peak corresponding to the protein thermal denaturation with no evident exothermic phenomena. However, the following cooling (purple 
curves) and the second heating (red curves) scans indicated only a partial reversibility of the process (lower signals).

Nevertheless, despite the partial reversibility in these experimental conditions (heating up to $95^{\circ} \mathrm{C}$ ), such a situation may correspond to a fully reversible process in the denaturation range, according to the literature [33]. In order to validate this hypothesis, a shorter heating/cooling cycle (up to $80^{\circ} \mathrm{C}$ ) was performed for My-PEG (1) samples, followed by a complete second heating scan (Fig. 3). We observed that the first and the second heating scans were fully overlapped (blue and red curves, respectively) confirming that the bioconjugation enhance the thermal denaturation reversibility of the protein with respect the reference. Moreover, the complete overlap between the second heating scan (red curve) and the first heating scan of the Fig.2a (reported in Fig. 3 as a grey trace) once again demonstrates our hypothesis and also verifies the reliability of the measurements. Again, these results were in agreement with the UV absorbance data. Indeed, the protein concentration in solution for the My-PEG (1) and My-PEG (2) samples was not significantly affected by the thermal scan.

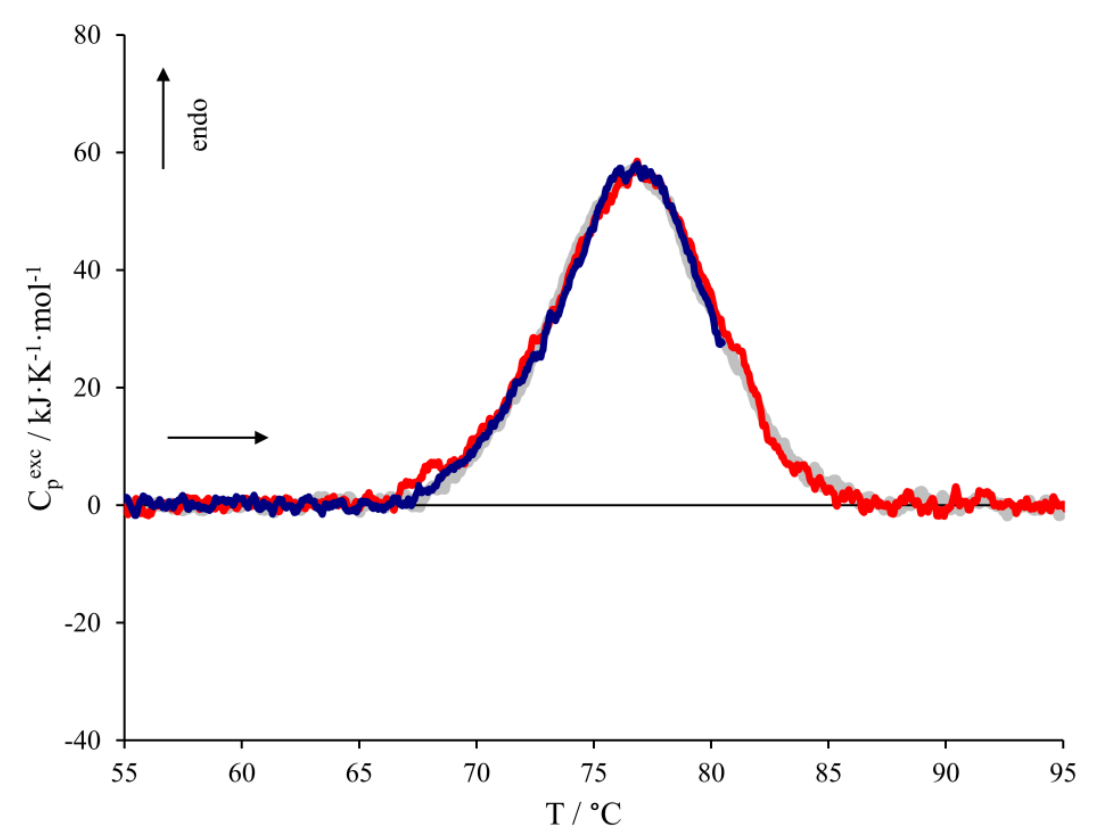

Fig. 3: Assessment of the My-PEG denaturation reversibility.

Micro-DSC thermograms for My-PEG (1) solutions $\left(1.5 \cdot 10^{-4} \mathrm{M}\right.$ in DPBS, $\mathrm{pH} 7.0,0.5^{\circ} \mathrm{C} \cdot \mathrm{min}^{-1}$ scan rate). First heating scan from 20 to $80^{\circ} \mathrm{C}$ (blue curve); second heating scan from 20 to $95^{\circ} \mathrm{C}$ (red curve). The first heating scan from 20 to $95^{\circ} \mathrm{C}$ (grey curve, which corresponds to the blue curve in Fig.2a) is also reported to highlight the reliability of the measurements.

Additional information on the bioconjugates in solution was provided by the UV-Vis absorption spectra of the samples in the wavelength range of 200-600 nm at room temperature. The absorbance spectra of My (black curve), My-PEG (1) (red curve) and My-PEG (2) (blue curve) are reported in Fig. 4 and indicate that the bioconjugation did not significantly affect the structure of the protein at room temperature. In particular, the profiles of all the samples presented a lower peak 
with the maximum at $280 \mathrm{~nm}$ and a more intense peak with the maximum at $409 \mathrm{~nm}$. This second peak, called Soret band [34], is due to the absorbance of heme group and it is exquisitely sensitive to changes in local environment [35]. The comparison between the spectra of myoglobin, My-PEG (1) and My-PEG (2) recorded at room temperature showed only slight differences in the Soret band intensity with respect the reference. These slight differences, that regards a local effect on the heme group, were the same in the two conjugates and seemed not to compromise the functionality of the protein at room temperature according to previous results of activity assays that showed a high preservation of the protein activity [27].

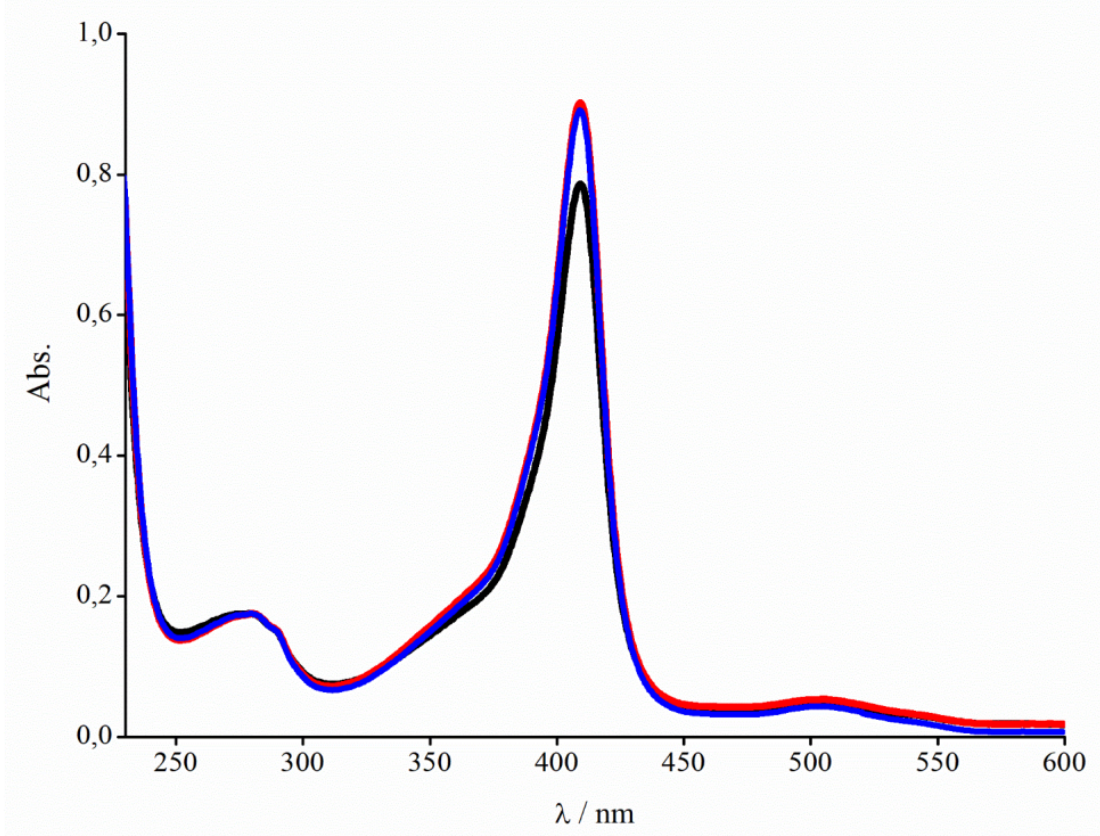

Fig. 4: Proteins spectroscopic characterization.

UV-Vis absorption spectra of the samples My (black curve), My-PEG (1) (red curve) and My-PEG (2) (blue curve), normalized per protein concentration. 


\subsection{Thermodynamic analysis}

The overall picture of My, My-PEG (1) and My-PEG (2) thermal unfolding is reported in Fig.5.

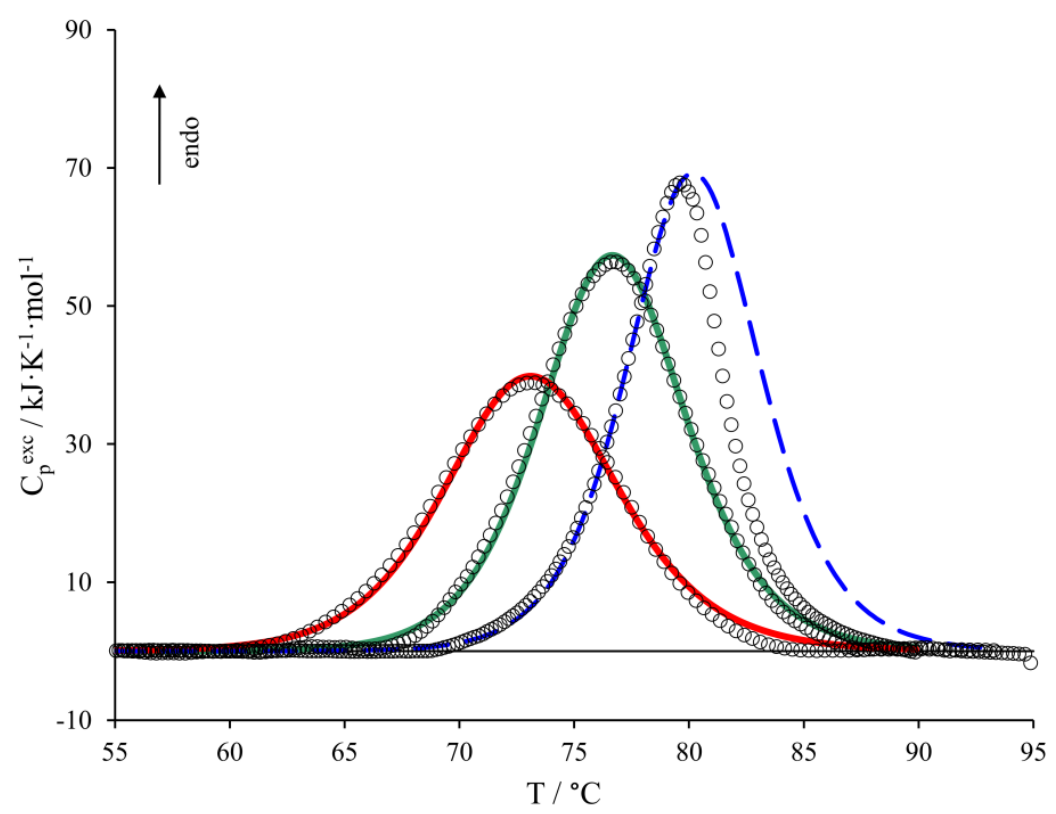

Fig. 5: Thermodynamic modelling of the DSC profiles.

Thermograms from the first heating scan for My (capillary cells calorimeter), $M y-P E G$ (1), My-PEG (2) (circles curves from the right to the left, respectively) $\left(1.5 \cdot 10^{-4} \mathrm{M}\right.$ in DPBS, $\mathrm{pH} 7.0,0.5^{\circ} \mathrm{C} \cdot \mathrm{min}^{-1}$ scan rate). The blue, green and red traces are the respective theoretical curves calculated according to a single step denaturation model.

It is evident that the bioconjugation has a destabilizing effect on this protein as regards both the denaturation enthalpy and temperature that are significantly decreased (see Table 1).

The reversibility results of the PEGylated conjugates clearly indicate that a thermodynamic analysis of the denaturation mechanism is allowed [33]. Accordingly, thermodynamic models [36,37] were applied in order to describe the thermal denaturation of the PEGylated conjugates. A single step model native-to-denatured state was sufficient to obtain a good fit for the two protein-polymer conjugates. A tentative fit was also attempted on the unmodified myoglobin's trace obtained by the capillary calorimeter. None thermodynamic model produced a satisfactory fit confirming that, in this case, the capillary cell was not totally able to avoid aggregation phenomena. However, although the denaturation and the aggregation processes may be concomitant, we may assume that the beginning of the peak is not strongly affected by the exothermic contribute. Therefore, for the sake of completeness and being aware of the possible miscalculation in the case of the unmodified protein, an attempt of a single step fit of the early part of the thermogram is also reported in Fig. 5, according to the one-state denaturation fitting model. The best fit parameters obtained by these fitting attempts are also reported in Table 1. 
Table 1: Denaturation enthalpy, $\Delta_{d} H^{\circ}$, and temperature, $T_{d}$ obtained by experimental DSC traces and bestfit values for My, My-PEG (1) and My-PEG (2) samples. The fit parameters were calculated according to a one state denaturation model.

\begin{tabular}{|c|c|c|c|c|}
\hline \multirow[t]{2}{*}{ System } & \multicolumn{2}{|c|}{ Experimental } & \multicolumn{2}{|c|}{$\begin{array}{c}\text { One state denaturation model } \\
\text { Best-Fit parameters }\end{array}$} \\
\hline & $\Delta_{d} H^{\circ} / \mathrm{kJ}^{\prime} \mathrm{mol}^{-1}$ & $T_{d} /{ }^{\circ} \mathrm{C}$ & $\Delta_{d} H^{\circ} / \mathrm{kJ}^{\prime} \mathrm{mol}^{-1}$ & $T_{d} /{ }^{\circ} \mathrm{C}$ \\
\hline Myoglobin & - & - & 540 & 80.7 \\
\hline$M y-P E G(1)$ & $480 \pm 25$ & $76.7 \pm 0.5$ & 485 & 76.7 \\
\hline$M y-P E G(2)$ & $415 \pm 25$ & $73.1 \pm 0.5$ & 410 & 73.1 \\
\hline
\end{tabular}

We may conclude that the destabilizing effect of the bioconjugation on this protein seems to follow the extent of the covalent modification, but do not alter the mechanism of thermal denaturation that remains a single step mechanism. Furthermore, taking into account the unaltered functionality of the proteins at room temperature [27], we may argue that the reduced thermodynamic stability of bioconjugated myoglobin, is mainly due to the altered solvent-surface interactions that maybe affect more the denatured state of the protein, that seems do not reach a complete random coil state because of the boundaries dictated by the bioconjugation, rather than to peculiar reorganizations of the native protein tertiary structure, that remains functional at room temperature. This scenario is further supported by the reversibility enhancement in the case of both bioconjugate systems.

Formally, the protein functionality and thermodynamic stability is dictated by the $\Delta_{d} G^{\circ}(T)=$ $G_{D}{ }^{\circ}(T)-G_{N}{ }^{\circ}(T)$ equation [28], i.e. by the difference of the standard Gibbs energy between the denatured and the native state. Accordingly, the unaltered functionality of the proteins, at room temperature, suggests that this difference, i.e. the $\Delta_{d} G^{\circ}\left(25^{\circ} \mathrm{C}\right)$, should be remain the same for the three systems. Unfortunately, the DSC measurements of the proteins investigated in our conditions (see the experimental section) did not permit to directly measure the heat capacity drop, $\Delta_{d} C_{P}$, for the tree systems, which represents an index of the solvent-exposed surface differences upon the denaturation [38-40] and in turn permits the $\Delta_{d} G^{\circ}\left(25^{\circ} \mathrm{C}\right)$ direct evaluation [28].

However, the calorimetric data $\left(\Delta_{d} H^{\circ}, T_{d}\right)$ reported in Table 1 allowed to attempt a thermodynamic visualization of this scenario in relative terms, i.e. assuming, as reference, an arbitrary value for the $\Delta_{d} C_{P}$ of the unmodified protein in the range of those reported in the literature [38-40] in order to evaluate the corresponding $\Delta_{d} G^{\circ}(T)$. In this way, the $\Delta_{d} C_{P}$, values for the PEGylated systems were estimated coherently, i.e. tentatively imposing the same $\Delta_{d} G^{\circ}\left(25^{\circ} \mathrm{C}\right)$ obtained for the unmodified myoglobin also for the two bioconjugates. The results of this attempt are shown in Fig. 6. Of course, the absolute $\Delta_{d} C_{P}$ values estimated for My-PEG (1) and My-PEG (2) depend on the $\Delta_{d} C_{P}$ value of the unmodified protein, here arbitrarily chosen, but in any case and in relative terms, this scenario predicts a severe reduction of $\Delta_{d} C_{P}$ for the PEGylated systems that follows the bioconjugation extent (Table 2), in line with all the experimental evidences in this work. 


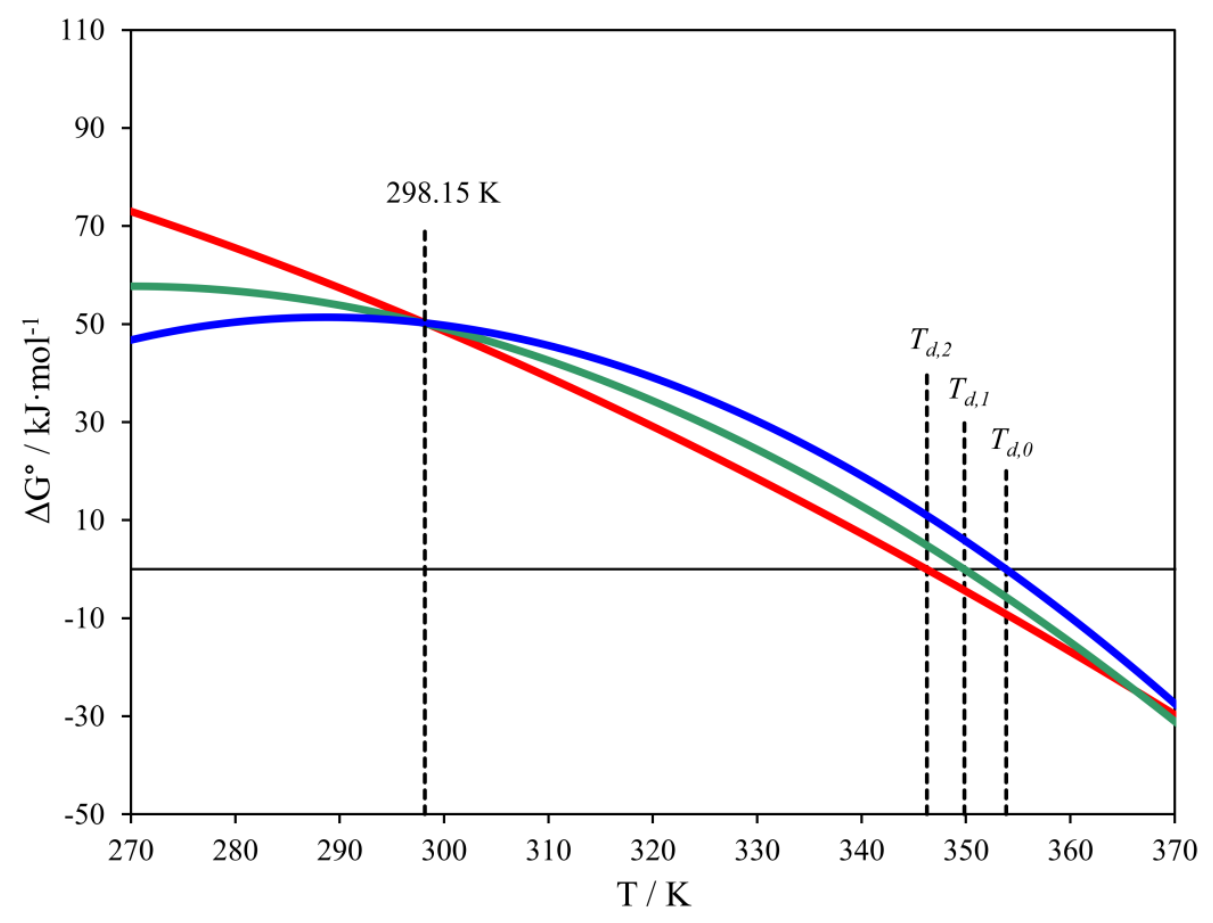

Fig. 6: Estimation of the standard Gibbs energy trends.

Calculated $\triangle_{d} G^{\circ}(T)$ for My (blue curve), My-PEG (1) (green curve) and My-PEG (2) (red curve) according to the data reported in Table 1 and Table 2. The denaturation temperatures of My, My-PEG (1) and My$P E G$ (2) are respectively indicated as $T_{d, 0}, T_{d, 1}$ and $T_{d, 2}$.

Table 2: Heat capacity drops and their relative reduction for $M y-P E G$ (1) and $M y-P E G$ (2) estimated by assuming the same $\Delta_{d} G^{\circ}\left(25^{\circ} \mathrm{C}\right)$ for all the systems and a nominal $\Delta_{d} C_{p}$ for My as reference.

\begin{tabular}{|c|c|c|}
\hline System & $\underset{1}{\Delta_{d} C_{p} / \mathrm{kJ}_{1} \mathrm{~mol}^{-1} \cdot \mathrm{K}^{-}}$ & $\begin{array}{l}\text { Relative } \\
\text { reduction }\end{array}$ \\
\hline Myoglobin & $7.5^{\mathrm{a}}$ & - \\
\hline$M y-P E G(1)$ & 5.4 & $\sim 30 \%$ \\
\hline$M y-P E G(2)$ & 1.9 & $\sim 75 \%$ \\
\hline
\end{tabular}

\section{Conclusions}

The overall results of this study indicate that the bioconjugation process provides a thermal destabilization of myoglobin. However, such a modification does not alter the denaturation mechanism, which remains as one-step process, and does not substantially compromise the protein native structure as well as its functionality. Moreover, the use of poly(ethylene glycol) as stealth 
agent confers an enhanced reversibility to the denaturation process. The thermodynamic interpretation of the data indicated that the bioconjugation influences the solvent-exposed protein surface difference between native and denatured state. This variation seemed to follow the extent of the bioconjugation and is coherent with the prevention of aggregation phenomena and the consequent observed reversibility.

The calorimetric approach provides relevant complementary information for the overall characterization of new classes of protein-polymer conjugates as a base for the rational design of new drugs and for a deeper understanding of the behaviour of the samples in solution.

\section{References}

[1] B. Leader, Q.J. Baca, D.E. Golan, Protein therapeutics: a summary and pharmacological classification, Nat. Rev. Drug Discov. 7 (2008) 21-39.

[2] H.A.D. Lagassé, A. Alexaki, V.L. Simhadri, N.H. Katagiri, W. Jankowski, Z.E. Sauna, C. Kimchi-Sarfaty, Recent advances in (therapeutic protein) drug development, F1000Research. 6 (2017) 113. doi:10.12688/f1000research.9970.1.

[3] B.J. Bruno, G.D. Miller, C.S. Lim, Basics and recent advances in peptide and protein drug delivery, Ther. Deliv. 4 (2014) 1443-1467. doi:10.4155/tde.13.104.Basics.

[4] S. a Marshall, G. a Lazar, J.R. Desjarlais, Rational design and engineering of therapeutic proteins., Drug Discov. Today. 8 (2003) 212-21.

[5] G.T. Hermanson, Bioconjugate techniques, 2nd ed., 2008.

[6] J. Herzberger, K. Niederer, H. Pohlit, J. Seiwert, M. Worm, F.R. Wurm, H. Frey, Polymerization of ethylene oxide, propylene oxide, and other alkylene oxides: Synthesis, novel polymer architectures, and bioconjugation, Chem. Rev. 116 (2016) 2170-2243.

[7] P. Mishra, B. Nayak, R.K. Dey, PEGylation in anti-cancer therapy: An overview, Asian J. Pharm. Sci. 11 (2016) 337-348.

[8] K. Knop, R. Hoogenboom, D. Fischer, U.S. Schubert, Poly(ethylene glycol) in drug delivery: Pros and cons as well as potential alternatives, Angew. Chemie - Int. Ed. 49 (2010) 62886308.

[9] W. Li, P. Zhan, E. De Clercq, H. Lou, X. Liu, Current drug research on PEGylation with small molecular agents, Prog. Polym. Sci. 38 (2013) 421-444.

[10] S.N.S. Alconcel, A.S. Baas, H.D. Maynard, FDA-approved poly(ethylene glycol)-protein conjugate drugs, Polym. Chem. 2 (2011) 1442.

[11] A. Abuchowski, J.R. Mccoy, N.C. Palczuk, Effect of Covalent Attachment of Polyethylene Glycol on Immunogenicity and Circulating Life of Bovine Liver Catalase, J. Biol. Chem. 252 (1976) 3582-3586.

[12] P. Caliceti, F.M. Veronese, Pharmacokinetic and biodistribution properties of poly(ethylene glycol)- protein conjugates, Adv. Drug Deliv. Rev. 55 (2003) 1261-1277.

[13] M. Swierczewska, K.C. Lee, S. Lee, M. Swierczewska, K.C. Lee, S. Lee, What is the future of PEGylated therapies?, Expert Opin. Emerg. Drugs. 20(4) (2015) 1-6. 
[14] E.M.P. Day, E. Lin, H.D. Maynard, Therapeutic Protein - Polymer Conjugates : Advancing Beyond PEGylation, J. Am. Chem. Soc. 136 (2014) 14323-14332.

[15] S. Schöttler, G. Becker, S. Winzen, T. Steinbach, K. Mohr, K. Landfester, V. Mailänder, F.R. Wurm, Protein adsorption is required for stealth effect of poly(ethylene glycol)- and poly(phosphoester)-coated nanocarriers, Nat. Nanotechnol. 11 (2016) 372-377.

[16] P. Bailon, A. Palleroni, C.A. Schaffer, C.L. Spence, W.-J. Fung, J.E. Porter, G.K. Ehrlich, W. Pan, Z.-X. Xu, M.W. Modi, A. Farid, W. Berthold, Rational Design of a Potent, LongLasting Form of Interferon: A $40 \mathrm{kDa}$ Branched Polyethylene Glycol-Conjugated Interferon a-2a for the Treatment of Hepatitis C, Bioconjug. Chem. 12 (2001) 195-202.

[17] D. Moatsou, J. Li, A. Ranji, A. Pitto-Barry, I. Ntai, M.C. Jewett, R.K. O’Reilly, Selfassembly of temperature-responsive protein-polymer bioconjugates, Bioconjug. Chem. 26 (2015) 1890-1899.

[18] Y.R. Gokarn, M. McLean, T.M. Laue, Effect of PEGylation on protein hydrodynamics, Mol. Pharm. 9 (2012) 762-773.

[19] D. Russo, M. Plazanet, J. Teixeira, M. Moulin, M. Härtlein, F.R. Wurm, T. Steinbach, Investigation into the Relaxation Dynamics of Polymer-Protein Conjugates Reveals Surprising Role of Polymer Solvation on Inherent Protein Flexibility, Biomacromolecules. 17 (2016) 141-147.

[20] B. Plesner, C.J. Fee, P. Westh, A.D. Nielsen, Effects of PEG size on structure, function and stability of PEGylated BSA, Eur. J. Pharm. Biopharm. 79 (2011) 399-405.

[21] Q. Wang, Liheng, Study on Effect of Polyethylene Glycol on Thermal Denaturation of Lysozyme by DSC, CNK-Chemistry Bioeng. (2010).

[22] T. Palm, R. Esfandiary, R. Gandhi, The effect of PEGylation on the stability of small therapeutic proteins., Pharm. Dev. Technol. 16 (2011) 441-8.

[23] J.A. Rodríguez-Martínez, R.J. Solá, B. Castillo, H.R. Cintrón-Colón, I. Rivera-Rivera, G. Barletta, K. Griebenow, Stabilization of $\alpha$-chymotrypsin upon PEGylation correlates with reduced structural dynamics, Biotechnol. Bioeng. 101 (2008) 1142-1149.

[24] E. Vernet, G. Popa, I. Pozdnyakova, J.E. Rasmussen, H. Grohganz, L. Giehm, M.H. Jensen, H. Wang, B. Plesner, H.M. Nielsen, K.J. Jensen, J. Berthelsen, M. Sundström, M. van de Weert, Large-Scale Biophysical Evaluation of Protein PEGylation Effects: In Vitro Properties of 61 Protein Entities, Mol. Pharm. 13 (2016) 1587-1598.

[25] Y. Moriyama, K. Takeda, Critical Temperature of Secondary Structural Change of Myoglobin in Thermal Denaturation up to $130{ }^{\circ} \mathrm{C}$ and Effect of Sodium Dodecyl Sulfate on the Change, J. Phys. Chem. B. 114 (2010) 2430-2434. doi:10.1021/jp908700j.

[26] Zalipsky, In Polymeric Drugs and Drug Delivery Systems, 1991.

[27] C. Pelosi, C. Duce, D. Russo, M.R. Tiné, F.R. Wurm, PPEylation of proteins: Synthesis, Activity, and Stability of Myoglobin-Polyphosphoester Conjugates, Eur. Polym. J. 108 (2018) 357-363.

[28] G. Barone, G., Del Vecchio, P., Fessas, D. Giancola, C., Graziano, Theseus: a new software package for the handling and analysis of thermal denaturation data of biological macromolecules, J. Therm. Anal. 39 (1993) 2779-2790. 
[29] M.H. Sleiman, R. Csonka, C. Arbez-Gindre, G.A. Heropoulos, T. Calogeropoulou, M. Signorelli, A. Schiraldi, B.R. Steele, D. Fessas, M. Micha-Screttas, Binding and stabilisation effects of glycodendritic compounds with peanut agglutinin, Int. J. Biol. Macromol. 80 (2015) 692-701. doi:10.1016/j.ijbiomac.2015.07.036.

[30] W.H. Press, B.P. Flannery, S.A. Teukolski, W.T. Weterling, Numerical recipes, Cambridge Univ. Press Cambridge, UK. (1989) 289-293.

[31] L. Kelly, L.A. Holladay, A Comparative Study of the Unfolding Thermodynamics of Vertebrate Metmyoglobins, Biochemistry. 29 (1990) 5062-5069.

[32] J.W. Tanner, P.A. Liebman, R.G. Eckenhoff, Volatile anesthetics alter protein stability, Toxicol. Lett. 100-101 (1998) 387-391.

[33] A. Barbiroli, F. Bonomi, P. Ferranti, D. Fessas, A. Nasi, P. Rasmussen, S. Iametti, Bound fatty acids modulate the sensitivity of bovine $\beta$-lactoglobulin to chemical and physical denaturation, J. Agric. Food Chem. 59 (2011) 5729-5737. doi:10.1021/jf200463u.

[34] Y. Kawamura-Konishi, H. Kihara, H. Suzuki, Reconstitution of myoglobin from apoprotein and heme, monitored by stopped-flow absorption, fluorescence and circular dichroism, Eur. J. Biochem. 170 (1988) 589-595.

[35] W. Gao, W. Liu, J.A. Mackay, E.J. Toone, A. Chilkoti, In situ growth of a stoichiometric PEG-like conjugate at a protein ' $\mathrm{s}$ N-terminus with significantly improved pharmacokinetics, PNAS. 106 (2009) 15231-15236.

[36] A. Ausili, A. Pennacchio, M. Staiano, J.D. Dattelbaum, D. Fessas, A. Schiraldi, S. D’Auria, Amino acid transport in thermophiles: Characterization of an arginine-binding protein from Thermotoga maritima. 3. Conformational dynamics and stability, J. Photochem. Photobiol. B Biol. 118 (2013) 66-73. doi:10.1016/j.jphotobiol.2012.11.004.

[37] K.E. Tsitsanou, C.E. Drakou, T. Thireou, A.V. Gruber, G. Kythreoti, A. Azem, D. Fessas, E. Eliopoulos, K. Iatrou, S.E. Zographos, Crystal and solution studies of the "plus-C" odorantbinding protein 48 from Anopheles gambiae: Control of binding specificity through threedimensional domain swapping, J. Biol. Chem. 288 (2013) 33427-33438. doi:10.1074/jbc.M113.505289.

[38] G.I. Makhatadze, P.L. Privalov, Energetics of protein structure., Adv. Protein Chem. 47 (1995) 307-425.

[39] J.K. Myers, C. Nick Pace, J. Martin Scholtz, Denaturant m values and heat capacity changes: Relation to changes in accessible surface areas of protein unfolding, Protein Sci. 4 (1995) 2138-2148.

[40] N. V. Prabhu, K.A. Sharp, Heat Capacity in Proteins, Annu. Rev. Phys. Chem. 56 (2005) 521-548. 


\section{Figure captions}

\section{Fig. 2: Myoglobin thermal denaturation.}

Thermograms for unmodified myoglobin $\left(1.5 \cdot 10^{-4} \mathrm{M}\right.$ in DPBS, $\mathrm{pH} 7.0,0.5^{\circ} \mathrm{C} \cdot \mathrm{min}^{-1}$ scan rate) obtained by using both a micro-DSC with cylindrical cell (blue curve) and a nano-DSC with capillary cells (red curve). The blue curve was smoothed in order to reduce the noise due to aggregation effects.

Fig. 2: PEGylation effect on the bioconjugates thermal stability.

Micro-DSC thermograms for My-PEG (1) and My-PEG (2) solutions ( $1.5 \cdot 10^{-4} \mathrm{M}$ in DPBS, $\mathrm{pH} 7.0$, $0.5^{\circ} \mathrm{C} \cdot \mathrm{min}^{-1} \mathrm{scan}$ rate) in panel a and $\mathrm{b}$, respectively. First heating scans from 20 to $95^{\circ} \mathrm{C}$ (blue curves); cooling scans from 95 to $20^{\circ} \mathrm{C}$ (purple curves); second heating scans from 20 to $95^{\circ} \mathrm{C}$ (red curves).

Fig. 3: Assessment of the My-PEG denaturation reversibility.

Micro-DSC thermograms for My-PEG (1) solutions $\left(1.5 \cdot 10^{-4} \mathrm{M}\right.$ in DPBS, $\mathrm{pH} 7.0,0.5^{\circ} \mathrm{C} \cdot \mathrm{min}^{-1} \mathrm{scan}$ rate). First heating scan from 20 to $80^{\circ} \mathrm{C}$ (blue curve); second heating scan from 20 to $95^{\circ} \mathrm{C}$ (red curve). The first heating scan from 20 to $95^{\circ} \mathrm{C}$ (grey curve, which corresponds to the blue curve in Fig.2a) is also reported to highlight the reliability of the measurements.

\section{Fig. 4: Proteins spectroscopic characterization.}

UV-Vis absorption spectra of the samples My (black curve), My-PEG (1) (red curve) and My-PEG (2) (blue curve), normalized per protein concentration.

\section{Fig. 5: Thermodynamic modelling of the DSC profiles.}

Thermograms from the first heating scan for My (capillary cells calorimeter), My-PEG (1), MyPEG (2) (circles curves from the right to the left, respectively) $\left(1.5 \cdot 10^{-4} \mathrm{M}\right.$ in DPBS, $\mathrm{pH} 7.0$, $0.5^{\circ} \mathrm{C} \cdot \mathrm{min}^{-1}$ scan rate). The blue, green and red traces are the respective theoretical curves calculated according to a single step denaturation model.

Fig. 6: Estimation of the standard Gibbs energy trends.

Calculated $\Delta_{\mathrm{d}} \mathrm{G}^{\circ}(\mathrm{T})$ for My (blue curve), My-PEG (1) (green curve) and My-PEG (2) (red curve) according to the data reported in Table 1 and Table 2. The denaturation temperatures of My, MyPEG (1) and My-PEG (2) are respectively indicated as $\mathrm{T}_{\mathrm{d}, 0}, \mathrm{~T}_{\mathrm{d}, 1}$ and $\mathrm{T}_{\mathrm{d}, 2}$. 